\title{
$\mu$-Opioid Receptors Are Localized to Extrasynaptic Plasma Membranes of GABAergic Neurons and Their Targets in the Rat Nucleus Accumbens
}

\author{
Adena L. Svingos, ${ }^{1}$ Akiyoshi Moriwaki, ${ }^{2}$ Jia Bei Wang,, ${ }^{2}$ George R. Uhl, ${ }^{2}$ and Virginia M. Pickel ${ }^{1}$ \\ ${ }^{1}$ Division of Neurobiology, Department of Neurology and Neuroscience, Cornell University Medical Center, New York, \\ New York 10021, and 2Intramural Research Program, National Institute on Drug Abuse, National Institutes of Health, \\ Bethesda, Maryland 20892, and Departments of Neurology and Neuroscience, Johns Hopkins University, Baltimore, \\ Maryland 21224
}

\begin{abstract}
The activation of $\mu$-opioid receptors in the nucleus accumbens (Acb) produces changes in locomotor and rewarding responses that are believed to involve neurons, including local $\gamma$-aminobutyric acid (GABA)ergic neurons. We combined immunogold-silver detection of an antipeptide antiserum against the cloned $\mu$-opioid receptor (MOR) and immunoperoxidase labeling of an antibody against GABA to determine the cellular basis for the proposed opioid modulation of GABAergic neurons in the rat Acb. MOR-like immunoreactivity (MOR-LI) was localized prominently to plasma membranes of neurons having morphological features of both spiny and aspiny cells, many of which contained GABA. Of 351 examples of profiles that contained MOR-LI and GABA labeling, $65 \%$ were dendrites. In these dendrites, MOR-LI was seen mainly along extrasynaptic portions of the plasma membrane apposed to unlabeled termi-
\end{abstract}

nals and/or glial processes. Dually labeled dendrites often received convergent input from GABAergic terminals and/or from unlabeled terminals forming asymmetric excitatory-type synapses. Of all profiles that contained both MOR and GABA immunoreactivity, $28 \%$ were axon terminals. MOR-containing GABAergic terminals and terminals separately labeled for MOR or GABA formed synapses with unlabeled dendrites and also with dendrites containing MOR or GABA. Our results indicate that MOR agonists could modulate the activity of GABA neurons in the Acb via receptors located mainly at extrasynaptic sites on dendritic plasma membranes. MOR ligands also could alter the release of GABA onto target dendrites that contain GABA and/or respond to opiate stimulation.

Key words: $\gamma$-aminobutyric acid; striatum; enkephalin; opiate; ultrastructure; electron microscopy; morphine
The nucleus accumbens (Acb) is an area that plays a critical role in opiate-induced behaviors (Goeders et al., 1984; West and Wise, 1988). Accordingly, administration of $\mu$-opioid receptor (MOR) agonists into the Acb produces a biphasic locomotor response, whereby an initial state of hypokinesia is followed by augmented hyperactivity (Pert and Sivit, 1977; Costall et al., 1978; Cunningham and Kelly, 1992; Meyer and Meyer 1993; Meyer et al., 1994). These behaviors are abolished by neuronal lesions of the Acb (Zito et al., 1985).

The MOR distribution in the Acb has been examined by autoradiography (Mansour et al., 1987; Tempel and Zukin, 1987) and light microscopic immunocytochemistry (Arvidsson et al., 1995; Kaneko et al., 1995; Mansour et al., 1995; Moriwaki et al., 1996; Svingos et al., 1996). These studies have shown a dense and patchy distribution of the receptor within the Acb. These patches of intense MOR labeling presumably occur in regions containing GABAergic neurons, because GABA is the major neurotransmitter in spiny projection neurons (Preston et al., 1979) and also is present in aspiny neurons (Bolam et al., 1983; Kita and Kitai,

Received Dec. 9, 1996; revised Jan. 14, 1997; accepted Jan. 16, 1997.

This work was supported by an Aaron Diamond Foundation Postdoctoral Fellowship to A.L.S., by National Institute on Drug Abuse (NIDA) Grant DA04600 to V.M.P., and by the NIDA Intramural Research Group. We thank Joy Hornung for her photographic expertise and Dr. Melissa Nirenberg for her critical commentary of this manuscript.

Correspondence should be addressed to Dr. Adena L. Svingos, Department of Neurology and Neuroscience, Division of Neurobiology, Cornell University Medical College, 411 East 69th Street, New York, NY 10021.

Copyright (C) 1997 Society for Neuroscience 0270-6474/97/172585-10\$05.00/0
1988). Both types of GABAergic neurons give rise to abundant local collaterals (Gerfen, 1988; Smith and Bolam, 1990) that form symmetric, inhibitory synapses (Carlin et al., 1980). In our initial studies in the Acb, MOR immunolabeling was localized to dendrites that received and axon terminals that formed symmetric junctions, suggesting possible cellular sites for functional interactions between MOR agonists and GABAergic neurons (Svingos et al., 1995, 1996).

Physiological evidence suggests that MOR agonists may modulate directly the activity of GABAergic neurons, a primary cell type of the Acb, and other brain regions (Gerfen, 1988). It has been shown that MOR activation causes hyperpolarization of GABA-containing neurons in the Acb, hippocampus, and ventral tegmental area (Zieglgansberger et al., 1979; Johnson and North, 1992; Siggins et al., 1995). MOR-mediated inhibition of GABAergic neurons could occur at their axon terminals (Capogna et al., 1993; Chieng and Christie, 1994), somata, and/or dendrites (Madison and Nicoll, 1988; Seward et al., 1991; Wimpey and Chavkin, 1991). MOR ligands also might reduce the efficacy of GABAergic transmission by modulation of the receptivity of GABAergic targets (Zieglgansberger and Bayerl, 1976; Churchill et al., 1991; Yuan et al., 1992).

The present study thus directly addresses the question of whether GABAergic neurons and/or their targets contain MOR immunoreactivity by combining electron microscopic immunocytochemical labeling of an antiserum against MOR and an antibody against GABA in the rat Acb. Our results show that the primary site of MOR localization is to extrasynaptic somatoden- 
dritic plasma membranes of GABAergic neurons and is also present in axon terminals that contain GABA. These results suggest that in the Acb MOR activation could modulate directly the activity of GABAergic neurons via changes in neuronal membrane receptivity and/or the release of GABA. We also show that GABAergic terminals form synapses with dually labeled neurons and MOR-immunoreactive neurons. These results suggest that MOR activation may modulate the GABAergic targets, some of which contain GABA.

\section{MATERIALS AND METHODS}

Antisera. A rabbit polyclonal antiserum was raised against an 18-aminoacid sequence (amino acids 381-398) in the C-terminal domain of the cloned MOR. The antiserum was characterized previously, using MORenriched transfected COS cells and Western immunoblots (Surratt et al., 1994). The specificity of the antibody was tested by comparison of the immunocytochemical labeling of rat brain tissue and transfected cells with MOR antiserum versus that seen with (1) preimmune serum, (2) omission of secondary antibodies, and (3) preincubation of the primary antibody with the C-terminal peptide or a random peptide of the same length. No detectable labeling was observed when the primary antiserum was eliminated. Preadsorption with the appropriate peptide also yielded significantly reduced labeling of brain tissue and transfected cells (Surratt et al., 1994). These data were confirmed by electron microscopy in the Acb (Svingos et al., 1996). In addition, Kaneko et al. (1995), Mansour et al. (1995), Arvidsson et al. (1995), and Moriwaki et al. (1996) showed a similar light microscopic heterogeneity of MOR-LI in the rat striatum with antisera raised against peptide sequences taken from the same portion of the receptor.

The rat anti-GABA antiserum was generously supplied by Dr. V.A. Bayer (Zeiss, Thornwood, NY). The specificity of this antibody has been shown previously, using immunoblot assay and preadsorption controls (Bayer and Pickel, 1991).

Tissue preparation. The methods for tissue preparation were based on those described previously by Leranth and Pickel (1989). Five adult (225-350 gm) male Sprague Dawley rats (Hilltop Laboratories, Scottdale, PA) were anesthetized with sodium pentobarbital $(100 \mathrm{mg} / \mathrm{kg}$, i.p. $)$. Then they were perfused through the ascending aorta with the following: $40 \mathrm{ml}$ of heparin $(1000 \mathrm{U} / \mathrm{ml}$ in $0.15 \mathrm{M} \mathrm{NaCl}), 50 \mathrm{ml}$ of acrolein $(3.75 \%$; Polyscience, Niles, IL), and $200 \mathrm{ml}$ of paraformaldehyde $(2 \%)$ in $0.1 \mathrm{M}$ phosphate buffer (PB, pH 7.4). The perfusates were delivered rapidly at a flow rate of $100 \mathrm{ml} / \mathrm{min}$ with a Masterflex infusion pump (Cole-Palmer, Chicago, IL). Then the brains were removed, cut into 4-5 mm coronal blocks, and post-fixed for $30 \mathrm{~min}$ in $2 \%$ paraformaldehyde. Sections through the Acb were cut on a vibratome at a thickness of $30-40 \mu \mathrm{m}$, incubated for $30 \mathrm{~min}$ in a solution of $1 \%$ sodium borohydride in $\mathrm{PB}$ to remove active aldehydes, and rinsed in PB. Tissue sections then were rinsed in Tris-buffered saline (TBS, $\mathrm{pH} 7.6$ ) and incubated for $30 \mathrm{~min}$ in $1 \%$ bovine serum albumin (BSA) in TBS to minimize nonspecific labeling.

Immunocytochemical detection. Tissue sections were processed for immunocytochemical localization of the MOR and GABA antisera by a pre-embedding peroxidase-immunogold dual-labeling method (Chan et al., 1990). The tissue sections were incubated for $48 \mathrm{hr}$ at $4^{\circ} \mathrm{C}$ in a primary antibody solution that contained the rabbit anti-MOR antiserum (1:5000) and the rat anti-GABA antiserum $(1: 10,000)$ in $0.1 \%$ BSA/TBS.

For immunoperoxidase labeling, the GABA antiserum was visualized by the avidin-biotin complex method (Hsu et al., 1981). Tissue sections were incubated for (1) $30 \mathrm{~min}$ in a 1:400 dilution of biotinylated goat anti-rat IgG (Amersham, Arlington Heights, IL) in $0.1 \%$ BSA, (2) $30 \mathrm{~min}$ in a 1:100 dilution of peroxidase-avidin complex, and (3) $6 \mathrm{~min}$ in a solution of $22 \mathrm{mg}$ of $3,3^{\prime}$-diaminobenzidine (DAB) and $10 \mu \mathrm{l}$ of $30 \% \mathrm{H}_{2} \mathrm{O}_{2}$ in $100 \mathrm{ml}$ of $0.1 \mathrm{M}$ TBS.

For immunogold-silver detection of MOR, tissue sections were (1) incubated for $2 \mathrm{hr}$ in colloidal gold $(1 \mathrm{~nm})$-labeled anti-rabbit IgG (1:50), (2) fixed for $10 \mathrm{~min}$ in $2 \%$ glutaraldehyde in PBS, and (3) reacted for 5-10 min with a silver solution from the intenSE kit (Amersham).

Tissue preparation for electron microscopy. Immunolabeled tissue sections were fixed for $60 \mathrm{~min}$ in $2 \%$ osmium tetroxide, dehydrated in a series of graded ethanols and propylene oxide, and incubated overnight in a 1:1 mixture of propylene oxide and Epon 812 (Electron Microscopy Sciences, Fort Washington, PA). Then the tissue was transferred to $100 \%$ Epon for 2-3 hr and flat-embedded between two pieces of Aclar plastic.
Ultrathin sections $(40-50 \mathrm{~nm})$ through the Acb at level 12 of the Paxinos and Watson (1986) rat brain atlas were cut with a diamond knife (Diatome, Fort Washington, PA). These sections were collected from the outer surface of the plastic-embedded tissue onto copper grids with an LKB ultramicrotome. Then these sections were counterstained with lead citrate (Reynolds, 1963) and uranyl acetate and examined with a Phillips 201 electron microscope.

Electron microscopic data analysis. For electron microscopic analysis, ultrathin tissue sections were examined at the tissue/Epon interface, where penetration of immunoreagents was maximal. Assessment of the relationship between MOR- and GABA-immunoreactive profiles was based on all observed contacts and colocalizations among immunolabeled cellular elements. The classification of labeled and unlabeled profiles was based on descriptions in Peters et al. (1991). Spiny somata were identified differentially by the presence of a nucleus having a round, unindented nuclear membrane and an abundance of cytoplasm. Aspiny somata were characterized as those with indented nuclei and scant cytoplasm. Dendrites were identified by the presence of postsynaptic densities and/or an abundance of ribosomes and both rough and smooth endoplasmic reticulum. Axon terminals $(0.2-1.5 \mu \mathrm{m})$ were identified by the presence of synaptic vesicles. Unmyelinated axons were smaller $(0.1-0.2 \mu \mathrm{m})$ than axon terminals and contained microtubules and occasional vesicles. Astrocytic processes were defined by their irregular contour and vacuous cytoplasm and occasional presence of glial microfilaments. Synapses were characterized as either symmetric (thin postsynaptic densities) or asymmetric (thick postsynaptic densities). Nonsynaptic contacts (appositions) were defined as closely spaced plasma membranes that lacked recognizable specializations but that were not separated by astrocytic processes.

Four to five vibratome sections from each of five animals were used to examine the cellular relationship between MOR- and GABAlabeled profiles. The incidence of contacts between and colocalization of MOR- and GABA-labeled elements was based on the total number of MOR-labeled profiles $(n=750)$. Specific cellular relationships between MOR- and GABA-immunoreactive profiles were assessed from the 524 MOR- and GABA-immunoreactive elements that either were in contact with or contained both antigens.

\section{RESULTS}

In the rat Acb, MOR-LI was localized mainly to extrasynaptic plasma membranes of somata, dendrites, and axon terminals, many of which also contained GABA immunoreactivity. Of 750 sampled MOR-labeled profiles, 524 either contained GABA or were in direct contact with GABA-immunoreactive profiles. Colocalization of the two antigens was detected most frequently in dendrites but also could be seen in somata and axon terminals. The contacts between MOR- and GABA-immunoreactive profiles included (1) inputs from terminals exclusively labeled for GABA onto dendrites containing GABA and/or MOR labeling, (2) inputs from dually labeled terminals onto differentially labeled dendrites, and (3) singly labeled axons apposed to common dendrites.

\section{MOR-LI was localized primarily to extrasynaptic plasma membranes of GABAergic somata, dendrites, and axon terminals}

MOR labeling was observed in GABAergic cell bodies that had either indented (Fig. $1 A$ ) or round nuclei (Fig. $1 B$ ), characteristic of medium aspiny and spiny neurons, respectively (Peters et al., 1991). The peroxidase labeling for GABA appeared mainly diffuse (Fig. $1 A$ ) or within distinct areas within the cytoplasm (Fig. $1 B)$. In general, the somata with indented nuclei seemed to contain more intense labeling for GABA (Fig. 1 $A$ ) than those with round nuclei (Fig. $1 B$ ). In both cells types, MOR-LI was distributed mainly along the plasma membrane but also was seen within the cytoplasm (Fig. $1 A, B$ ). Cytoplasmic MOR-LI was localized frequently to saccules of smooth endoplasmic reticulum or Golgi lamellae. Somata containing MOR and GABA immunoreactivity most often were apposed to unlabeled glial processes (Fig. 

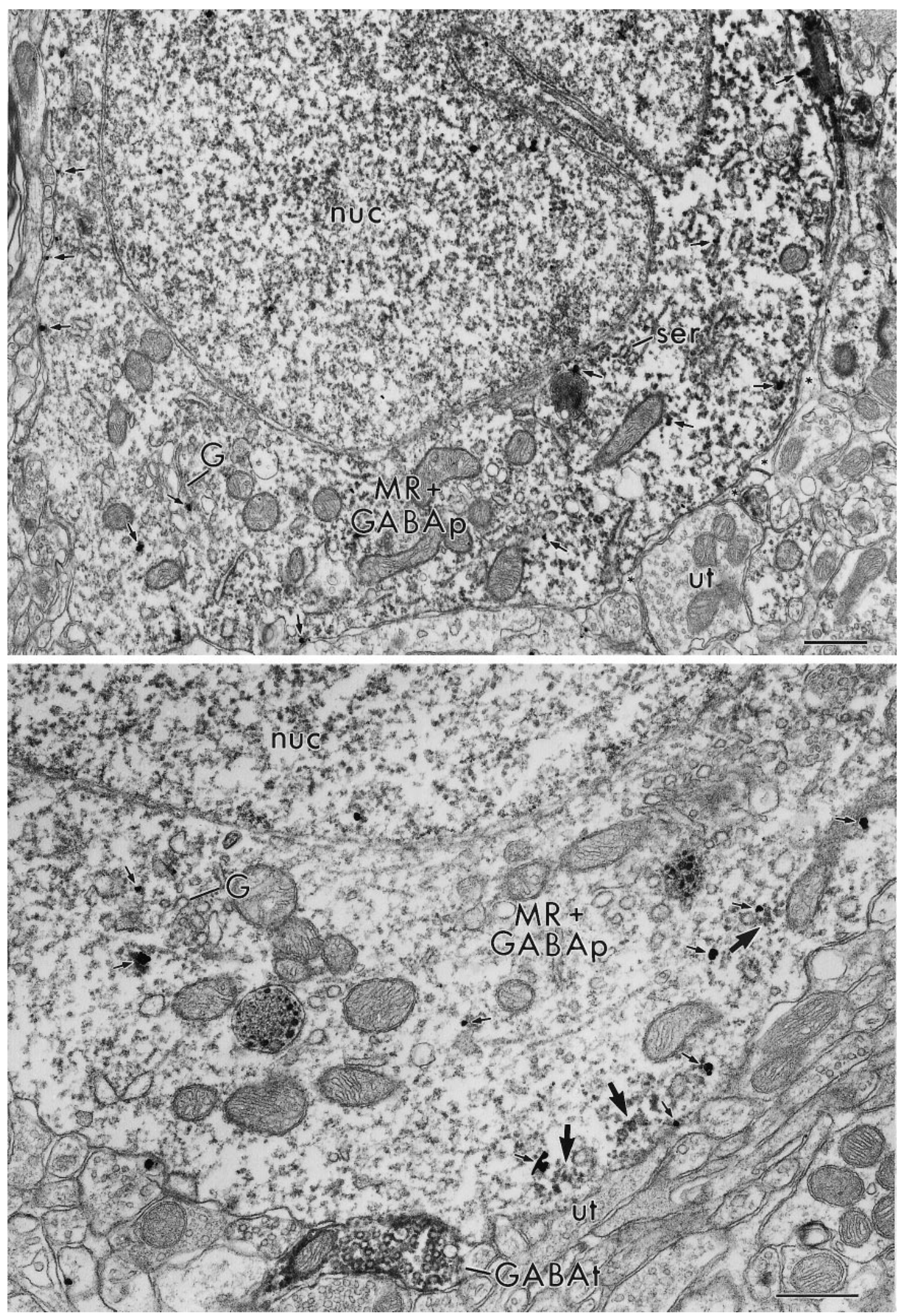

Figure 1. Electron micrographs showing immunogold MOR labeling and immunoperoxidase labeling for GABA localized to the perikaryon of medium aspiny-type $(A)$ and spiny-type $(B)$ somata $(M R+G A B A p)$. In $A$ and $B$, MOR-LI is identified by dense immunogold-silver deposits (small arrows) distributed along the cytoplasmic surface of the plasma membrane and dispersed within the cytoplasm, sometimes near Golgi lamellae $(G)$ and saccules of endoplasmic reticulum (ser). $A$, The peroxidase reaction product for GABA is intense and appears diffusely distributed throughout the cytoplasm. GABA immunoreactivity in $B$ is relatively light and is distributed sparsely near the perikaryal plasma membrane (arrowheads). Both somata are apposed to unlabeled terminals $(u t)$, whereas the cell body in $A$ is contacted by glial processes (asterisks). The dually labeled cell body in $B$ is contacted by a GABAergic axon terminal $(G A B A t)$. nuc, Nucleus. Scale bars, $0.5 \mu \mathrm{m}$. 
$1 A$ ) and axon terminals (Fig. $1 A, B$ ) but sometimes were contacted by GABAergic terminals (Fig. $1 B$ ).

Of the profiles in which MOR-LI and GABA were colocalized, $65 \%$ were dendrites and dendritic spines $(n=351)$. The dendritic peroxidase GABA labeling was either intense, resembling that seen in aspiny neurons, or lighter, as was seen in the spiny type somata (Fig. 2A). These dendrites also varied in size. Small dendrites or spines contained little smooth endoplasmic reticulum and were $\sim 0.5 \mu \mathrm{m}$ in diameter (Fig. $2 B, C$ ). Larger dendrites contained more abundant smooth endoplasmic reticulum and had diameters as large as $2.5 \mu \mathrm{m}$ (Fig. $2 A$ ).

The dually labeled dendrites were contacted by terminals both with (discussed below) and without detectable GABA immunoreactivity (Fig. 2). Those terminals without detectable GABA labeling did not seem to form synapses with the labeled dendrites. In contrast, dually labeled dendritic spines often received asymmetric synapses from unlabeled terminals. Some of these asymmetric junctions showed prominent perforations (Fig. 2C). Astrocytic processes sometimes were apposed to the dually labeled dendrites and axo-spinous complexes (Fig. 2C).

Within the GABA-containing dendrites and dendritic spines, MOR immunogold-silver particles most often were associated with extrasynaptic portions of the dendritic plasma membrane, where they were apposed to unlabeled terminals and glial processes (Fig. 2). In the sections that were examined, MOR-LI was not detected at postsynaptic densities.

Of 351 sampled profiles that contained both MOR and GABA labeling, $28 \%$ were axon terminals $(n=147)$. These terminals contained an abundance of diffuse peroxidase reaction product for GABA and measured between $0.4-1.2 \mu \mathrm{m}$ in diameter. Dually labeled axon terminals frequently were apposed to unlabeled dendrites (Fig. $3 A$ ), but in some cases they also formed symmetric synapses with dendrites containing either MOR-LI (Fig. $3 A$ ) or GABA labeling (Fig. 3B).

Within the dually labeled axons, the MOR gold-silver particles were localized mainly within the cytoplasm near small vesicles and/or mitochondria (Fig. 3A,B). Less frequently, MOR gold-silver particles were in contact with plasma membranes of axon terminals (Fig. $3 A$ ). In those cases in which MOR-LI was localized to axonal plasma membranes, gold-silver particles were not seen immediately within the presynaptic membrane specializations (Fig. $3 A$ ).

\section{Dendrites containing GABA and MOR immunoreactivity receive synaptic input from terminals with and without GABA}

The majority of dendrites that contained both MOR and GABA immunoreactivity received contacts from GABAergic terminals. The GABAergic terminals, which measured $0.2-1.2 \mu \mathrm{m}$ in diameter, were characterized by diffuse immunolabeling and round, tightly packed synaptic vesicles (Figs. $2 A, 4$ ). The GABA-immunoreactive terminals also were apposed to small unmyelinated axons, astrocytic processes, and other unlabeled terminals. Within the dually labeled dendrites, MOR gold-silver particles were located prominently on the plasma membrane at sites distal to GABAergic contacts. The MOR-labeled particles usually were distributed along segments of the plasma membrane that were apposed to unlabeled glial processes or other unlabeled axon terminals. These unlabeled terminals ranged in diameter from $0.2-1.2 \mu \mathrm{m}$ and mainly contained round vesicles that were loosely packed.

\section{Dendrites containing MOR immunolabeling receive synaptic input from terminals with and without GABA}

A portion of the GABA-containing terminals was apposed to dendrites that contained only MOR labeling. These GABAergic terminals were defined by diffuse peroxidase labeling and were between $0.2-0.9 \mu \mathrm{m}$ in diameter. MOR-labeled dendrites occasionally received input from multiple GABAergic terminals, some of which formed recognizable symmetric synapses (Fig. 4). MOR gold-silver particles were localized mainly to the plasma membrane but also were found within the cytoplasm of these dendrites and their spines. Although a few gold-silver deposits were localized to plasma membranes at sites near GABAergic synapses, most were seen along plasma membranes, apposed to unlabeled profiles (Fig. 4). The unlabeled profiles included other dendrites, astrocytic processes, and axon terminals.

\section{MOR and GABA immunoreactivity were localized to apposed axons}

From all sampled MOR- or GABA-labeled profiles that were in contact, a small proportion showed MOR and GABA labeling in separate, apposed axons terminals or small unmyelinated axons. GABA-containing axons and axon terminals ranged in size from $0.2-0.5 \mu \mathrm{m}$ in diameter and were characterized by diffusely distributed peroxidase reaction product. MORlabeled axons and axon terminals ranged in size from $0.4-0.8$ $\mu \mathrm{m}$ in diameter and contained round, loosely packed vesicles. The MOR gold-silver particles were located primarily along the plasma membranes (Fig. 3C,D), but some also were seen near small vesicles (Fig. $3 C$ ). Separately labeled axon terminals often were apposed to dendrites, most of which were unlabeled, but some contained MOR-LI (Fig. 3C). These dendrites were apposed to small GABA-immunoreactive axons and other unlabeled terminals. Separately labeled small, unmyelinated axons appeared within groups of other small, unlabeled axons (Fig. 3D).

\section{DISCUSSION}

The present study provides the first ultrastructural evidence that, in the rat Acb, MOR is localized prominently to extrasynaptic somatodendritic plasma membranes of GABA-containing spiny and aspiny neurons. This suggests that MOR ligands have the potential to alter membrane receptivity via ion channel permeability or second messengers in GABAergic cell types present in this region. Our results also indicate that these postsynaptic mechanisms may be complemented or opposed by MOR activation within GABA-containing axon terminals. These dual modulatory sites are likely to contribute to opiate-induced disinhibition and some of the behavioral changes ascribed to MOR stimulation.

\section{Methodological considerations}

The MOR peptide sequence against which our antibody was raised represents, to date, the receptor mainly responsible for morphine effects in producing analgesia and behavioral reward. The term $\mu$-opioid receptor-like immunoreactivity (MOR-LI) describes the localization of the antibody used in this study and includes the possibility that the antiserum also may recognize structurally similar proteins. On the basis of several lines of evidence that were addressed in Materials and Methods, however, we believe that the MOR labeling in this and previous studies is specific (Surratt et al., 1994; Moriwaki et al., 1996; Svingos et al., 1996).

The methods used in this study could underestimate the num- 

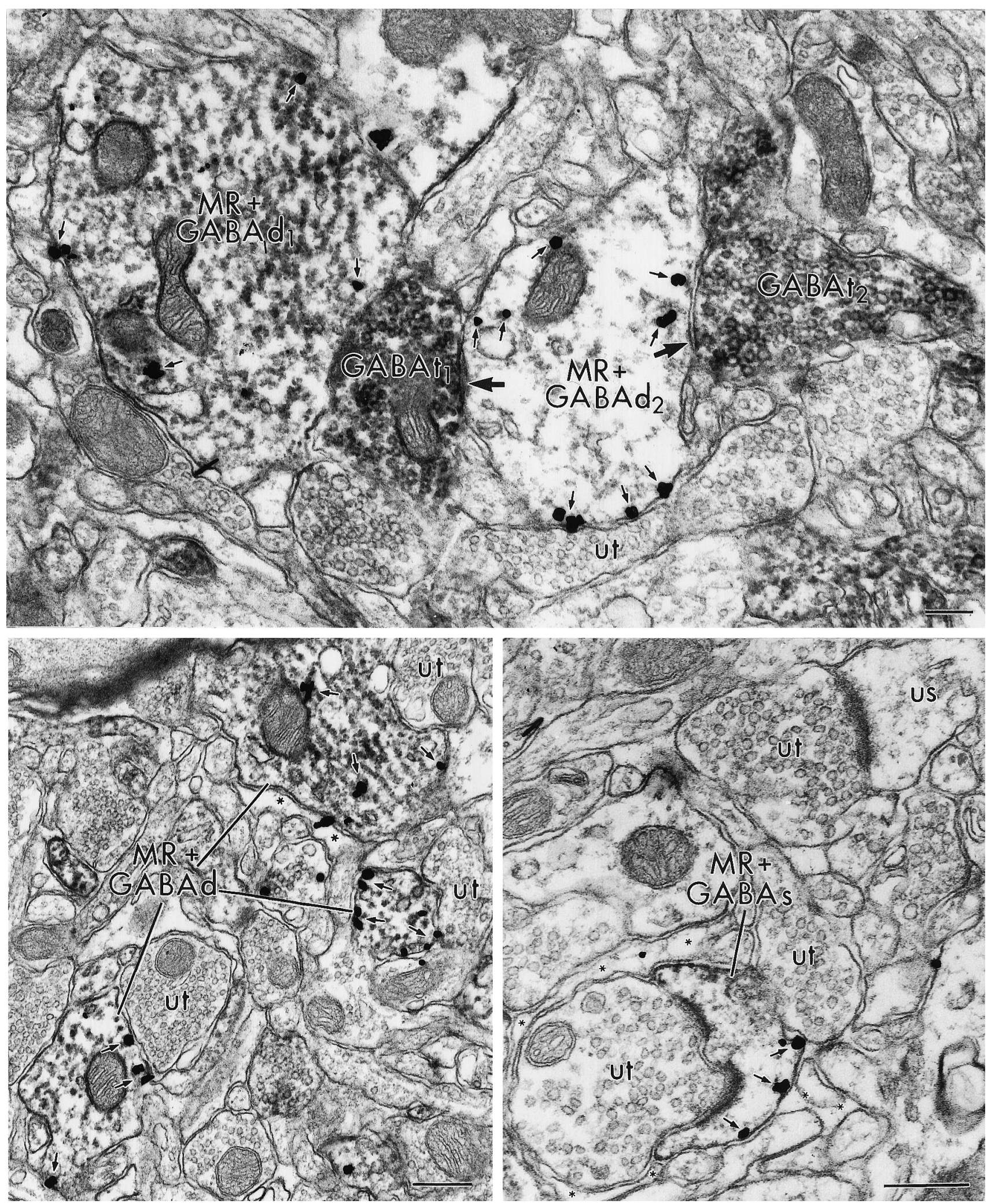

Figure 2. Electron micrographs showing dually labeled dendrites and dendritic spines apposed to GABA-immunoreactive and unlabeled terminals. The dually labeled dendrites in $A(M R+G A B A d)$ are apposed to GABA-containing terminals $\left(G A B A t_{l, 2}\right)$. The three dually labeled dendrites in $B(M R+$ $G A B A d)$ are apposed to terminals that lack detectable GABA immunoreactivity $(u t)$. $C$, Shown is a dendritic spine containing immunolabeling for MOR-LI and GABA $(M R+G A B A s)$ contacted by two unlabeled terminals $(u t)$, one of which forms a perforated asymmetric synapse. The axo-spinous complex is enveloped by an astrocytic process (asterisks). In the same field, an unlabeled spine (us) is apposed to an unlabeled terminal (ut) that forms an asymmetric synapse. In $A-C$, MOR immunogold-silver particles (small arrows) are located primarily along extrasynaptic portions of the dendritic plasma membrane. Scale bars, $0.3 \mu \mathrm{m}$. 

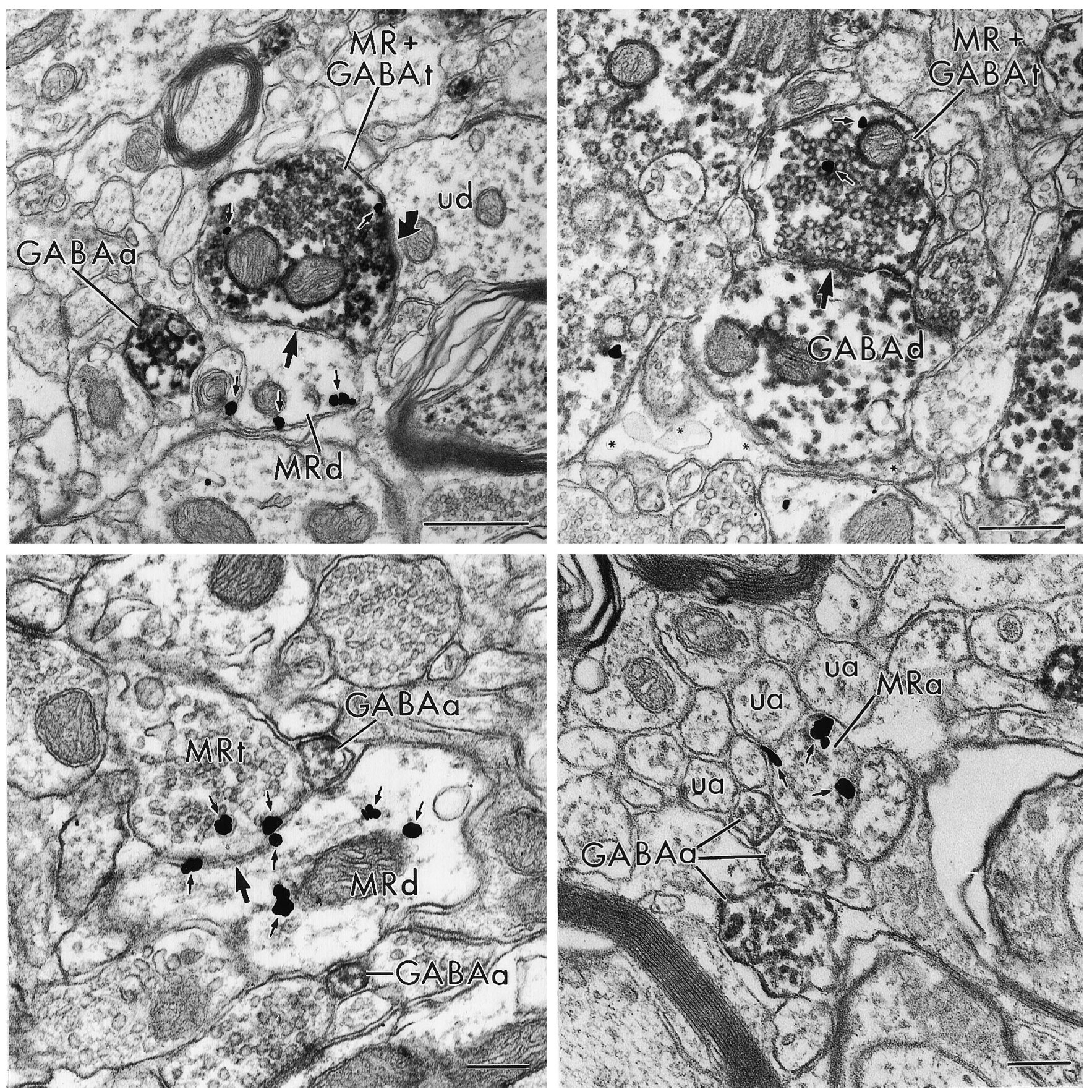

Figure 3. Electron micrographs showing MOR immunogold-silver labeling and immunoperoxidase labeling for GABA in the same or apposed axons and axon terminals. $A$, A dually labeled axon terminal $(M R+G A B A t)$ is apposed to (large arrow) a dendrite that contains MOR-LI (MRd). $M R+G A B A t$ also forms a symmetric synapse (curved arrow) with an unlabeled dendrite $(u d)$ ). In the same field, a presynaptic axon is immunoreactive for GABA $(G A B A a)$. B, A dually labeled axon terminal $(M R+G A B A t)$ forms a symmetric contact (large arrow) with a dendrite labeled for GABA $(G A B A d)$, which is apposed to an astrocytic process (asterisks). In $A$ and $B$, the axonal MOR immunogold-silver deposits (small arrows) are located mainly near synaptic vesicles and mitochondrial membranes, whereas the dendritic MOR-LI (in $A$ ) is localized to the plasma membrane. $C$, Shown is a MOR-labeled axon terminal $(M R t)$ apposed to a GABA-immunoreactive axon $(G A B A a)$. Both axons are apposed to a dendrite containing MOR gold-silver particles (MRd). $D$, Shown is a bundle of unmyelinated axons, some of them are unlabeled (ua), whereas others are exclusively MOR-labeled (MRa) or GABA-labeled $(G A B A a)$. Scale bars, $0.2 \mu \mathrm{m}$.

ber of MOR/GABA associations. Underestimations of the number of singly or dually labeled processes may be attributed to differential detection of immunoperoxidase, as compared with the immunogold-silver (Chan et al., 1990). The immunogold-silver method provides greater subcellular resolution but lower sensitivity than the immunoperoxidase method, which might contribute to artifactual differential labeling (Leranth and Pickel, 1989). Collection of thin sections at the Epon/tissue interface was used to minimize this problem. These considerations suggest that the incidence of coexistence and synaptic associations between the two antigens is at least as great as, if not greater than, that which we have observed here. 


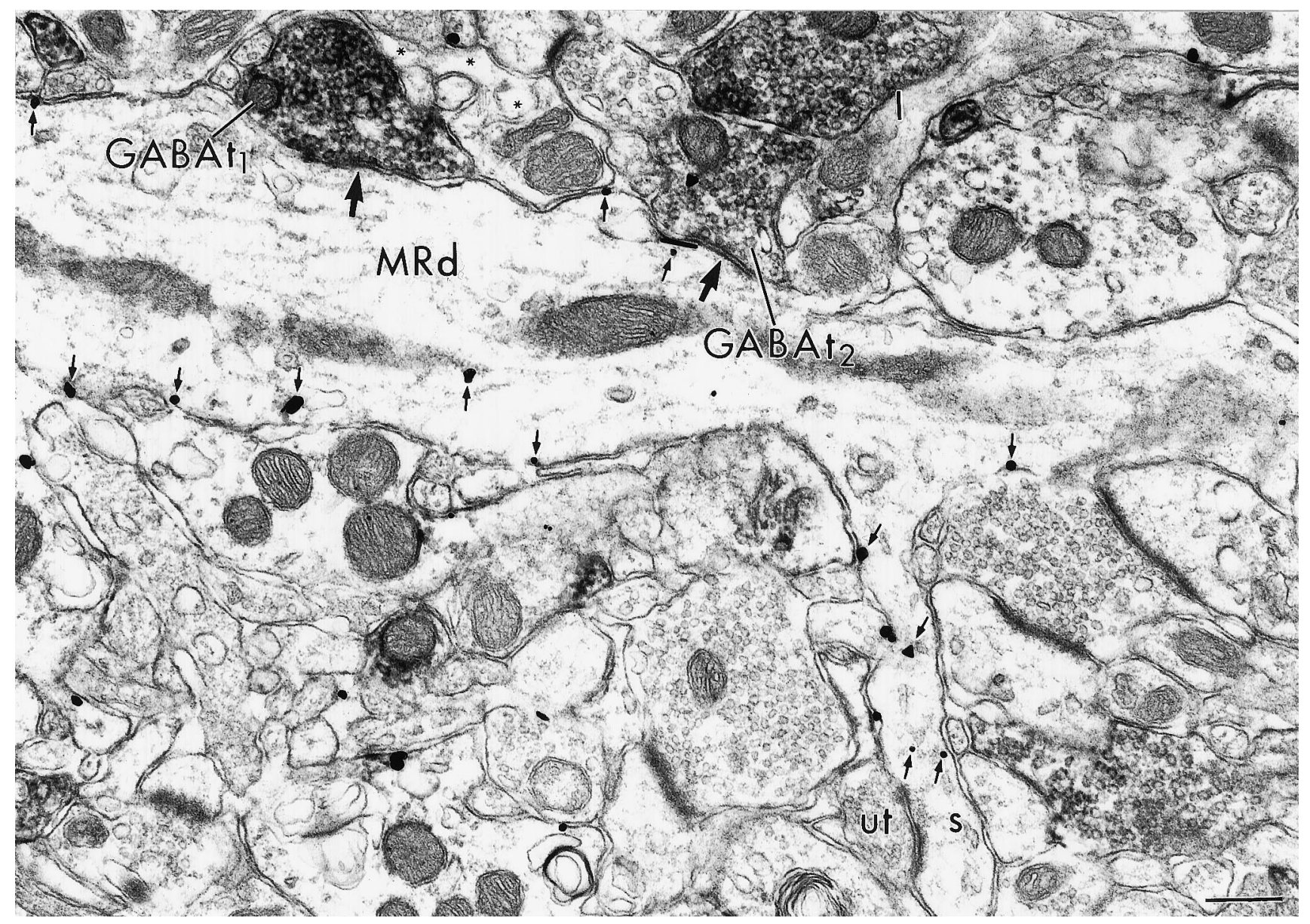

Figure 4. Electron micrograph showing immunoperoxidase reaction product for GABA in axon terminals that contact a MOR immunogold-labeled dendrite (small arrows). The MOR-labeled longitudinally cut dendrite $(M R d)$ receives input from two GABA-immunoreactive axon terminals $\left(G A B A t_{1,2}\right)$ that form symmetric synapses (large arrows). MRd has an emergent spine head or heads that receive an asymmetric synapse from an unlabeled terminal (ut). $s$, Spine. Scale bar, $0.27 \mu \mathrm{m}$.

\section{Spiny and aspiny GABAergic somata and dendrites contain MOR labeling}

Neuronal perikarya that contained MOR-LI had either unindented nuclei and sparse GABA immunoreactivity or indented nuclear membranes and more densely distributed GABA labeling. In the Acb, round nuclear membranes are characteristic of spiny neurons, with indented nuclei found in aspiny neurons (Ribak et al., 1979; Bolam et al., 1985; Pasik et al., 1988; Pickel et al., 1988). Furthermore, some dually labeled dendrites had spines, whereas some did not. MOR-immunoreactive dendrites also varied greatly in their density of peroxidase labeling for GABA. This suggests that MOR was localized to spiny neurons, defined as those having a relative lack of peroxidase reaction product, as well as the more heavily labeled aspiny neurons (Bradley et al., 1983; Oertel and Mugnaini, 1983; Aronin et al., 1984). Because spiny GABAergic cells are projection neurons (Chang and Kitai, 1985; Churchill et al., 1991) and aspiny neurons are intrinsic (Bolam et al., 1983; Kita and Kitai, 1988), our results indicate that MOR ligands are well positioned to modulate the activity of both types of GABAcontaining neurons in the Acb.

Our findings also show a preferential distribution of MOR-LI to extrasynaptic portions of spiny and aspiny GABAergic somatodendritic plasma membranes. This is consistent with electrophysiological evidence indicating that MOR agonists can increase potassium con- ductance and decrease calcium currents of GABAergic somata and dendrites (Madison and Nicoll, 1988; Seward et al., 1991; Wimpey and Chavkin, 1991). This has been shown to result in membrane hyperpolarization in the striatum and Acb (Jiang and North, 1992; Yuan et al., 1992). This hyperpolarization may occur via MORlinked G-protein-gated inward rectifier potassium or calcium channels, both of which have been localized to plasma membranes of perikarya and dendrites in various brain regions (Bausch et al., 1995; Westenbroek et al., 1995; Ponce et al., 1996; Drake et al., 1997). Through these channels, MOR agonists may inhibit postsynaptic potentials and/or attenuate the propagation of actions potentials (Galarraga et al., 1989). In this and previous studies, we have shown that the subcellular distribution of MOR is similar to that of $G_{i} \alpha$, a MOR-linked G-protein (Aronin and DiFiglia, 1992; Svingos et al., 1996). This indicates possible sites for receptor-mediated signal transduction along extrasynaptic dendritic plasma membranes of GABA-containing neurons. Taken together, the prominent localization of MOR-LI along extrasynaptic plasma membranes of GABAcontaining perikarya and dendrites suggests that the receptor is involved in opiate-mediated ion fluxes and second messenger functions in both intrinsic and projection neurons of the Acb.

Our data show that MOR-LI also is localized to extrasynaptic plasma membranes of GABA-containing dendritic spines. A portion of these dually labeled spines received asymmetric perforated 
synapses from unlabeled terminals. Based on their morphology, these unlabeled terminals most likely contain glutamate (Hendry et al., 1983). Within the Acb, the NMDA glutamate receptor also shows a prominent distribution to dendritic spines, some of which receive perforated synapses (Gracy and Pickel, 1996). In addition, NMDA-labeled dendritic spines have been shown to contain MOR immunoreactivity (K. N. Gracy, A. L. Svingos, V. M. Pickel, unpublished observations). It is hypothesized that stimulation of NMDA receptors within spines underlies some forms of plasticity, which may be manifested via changes in the number of perforated synapses (Manabe et al., 1992) (for review, see Edwards, 1995). Therefore, our data may reflect an anatomical locus for MORmediated adaptive changes associated with opiate use that occur via modulation of GABAergic dendritic spines.

\section{MOR and GABA immunoreactivity are colocalized in axon terminals}

The present data provide direct evidence for plasmalemmal and cytoplasmic localizations of MOR-LI in GABA-containing terminals. Our results support data from other brain regions, which suggest that activation of MOR inhibits GABA release (Lambert et al., 1991; Xie et al., 1992; Capogna et al., 1993; Lupica, 1995). MOR-mediated inhibition of GABA release may occur via G-protein-coupled potassium channels (North et al., 1987; Wimpey and Chavkin, 1991; Chieng and Christie, 1994), calcium currents (Seward et al., 1991), and/or fusion of synaptic vesicles (Capogna et al., 1993; Lupica, 1995). Interestingly, calcium channels and $\mathrm{G}_{\mathrm{i}} \alpha$ have been localized to axon terminals (Aronin and DiFiglia, 1992; Westenbroek et al., 1995), the latter sharing a MOR-like subcellular distribution. The distribution of axonal MOR is consistent with coupling of the receptor to ion channel/ G-protein complexes through which the receptor may inhibit GABA release. The release of GABA may be attenuated by two distinct mechanisms, one through permeability of plasma membranes via axonal ion channels and another through mediation of docking of synaptic vesicles to presynaptic specializations (Bourne, 1988; Mizoguchi et al., 1990). Our results indicate that inhibition of GABA release from axon terminals by MORselective ligands may reduce inhibitory input to GABA- and non-GABA-containing neurons, thus contributing to the disinhibitory effects of opiates in the Acb. Our results also show that axons separately labeled for either MOR or GABA sometimes are apposed. The lack of axo-axonic synapses and the relative paucity in which we observed these associations suggests that presynaptic inhibition is not likely to occur via axo-axonic contacts.

\section{Dendrites that colocalize MOR and GABA immunoreactivity receive input from GABAergic and excitatory afferents}

Our data show that dually labeled dendrites receive convergent input from GABAergic terminals that form symmetric synapses on their shafts and unlabeled terminals that form excitatory-type synapses with their spines (Hendry et al., 1983). In the Acb and other brain regions, MOR stimulation can result in a reduction of GABA-mediated inhibitory postsynaptic potentials and enhanced glutamatergic excitatory postsynaptic potentials (Dingledine, 1981; Xie et al., 1992; Siggins et al., 1995). It has been postulated that this circuitry may underlie opiate-induced disinhibition (Madison and Nicoll, 1988; Yuan et al., 1992). Our data provide anatomical support for this hypothesis and are consistent with the presence of neurons in the Acb that are disinhibited by MOR agonists (Hakan and Henriksen, 1987).

We also show that GABA-containing terminals form symmetric synapses with dendrites containing only MOR labeling. This suggests that MOR agonists and GABA dually modulate the output of some Acb neurons. The transmitter in these targets neurons is unknown but may include cells with undetectable levels of GABA or other neurotransmitters. Because GABAergic terminals in the striatum form synapses with acetylcholine-containing neurons (Zaborszky et al., 1986) and MOR ligands modulate acetylcholine release (Heijna et al., 1990), these neurons are likely to be cholinergic. This possibility is currently under investigation.

\section{Functional implications}

Modulation of GABAergic neurotransmission via stimulation of opioid receptors is believed to be one of the major substrates for the disinhibitory effects of opiates throughout the CNS (Zieglgansberger et al., 1979; Madison and Nicoll, 1988; Johnson and North, 1992; Siggins et al., 1995). Our localization of MOR-LI to extrasynaptic plasma membranes of aspiny and spiny GABAergic neurons indicates that opiates modulate the postsynaptic responses of local inhibitory and projection cells (Preston et al., 1979; Bolam et al., 1983; Churchill et al., 1991; Van Bockstaele and Pickel, 1995). Furthermore, MOR localization within GABAcontaining terminals indicates that the receptor may act as an presynaptic receptor, inhibiting the release of GABA via local sources of enkephalin, which also are known to be colocalized within GABAergic neurons (Aronin et al., 1984). Taken together, these observations suggest that MOR-mediated inhibition of GABA receptivity and release in the Acb may cause disinhibition of GABAergic targets, thereby accounting for the behavioral changes associated with opiate use (Hubner and Koob, 1990; Kalivas et al., 1993; Siggins et al., 1995).

\section{REFERENCES}

Aronin N, DiFiglia M (1992) The subcellular localization of the G-protein $\mathrm{G}_{\mathrm{i}} \alpha$ in the basal ganglia reveals its potential role in both signal transduction and vesicle trafficking. J Neurosci 12:3435-3444.

Aronin N, DiFiglia M, Graveland GA, Schwartz WJ, Wu J-Y (1984) Localization of immunoreactive enkephalins in GABA synthesizing neurons of the rat neostriatum. Brain Res 300:376-380.

Arvidsson U, Reidl M, Chakrabarti S, Lee J-H, Nakano AH, Dado RJ, Loh HH, La P-Y, Wessendorf MW, Elde R (1995) Distribution and targeting of a $\mu$-opioid receptor (MOR1) in brain and spinal cord. J Neurosci 15:3328-3341.

Bausch SB, Patterson TA, Ehrengruber MU, Lester HA, Davidson N, Chavkin C (1995) Colocalization of mu opioid receptors with GIRK1 potassium channels in the rat brain: an immunocytochemical study. Receptors Channels 3:221-241.

Bayer VE, Pickel VM (1991) GABA-labeled terminals form proportionally more synapses with dopaminergic neurons having low densities of tyrosine hydroxylase immunoreactivity in rat ventral tegmental area. Brain Res 559:44-55.

Bolam JP, Clarke DJ, Smith AD, Somogyi P (1983) A type of aspiny neuron in the rat neostriatum accumulates $\left[{ }^{3} \mathrm{H}\right] \gamma$-aminobutyric acid: combination of Golgi-staining, autoradiography, and electron microscopy. J Comp Neurol 12:121-134.

Bolam JP, Powell JF, Wu JY, Smith AD (1985) Glutamate decarboxylase-immunoreactive structures in the rat neostriatum: a correlated light and electron microscopic study including a combination of Golgi impregnation with immunocytochemistry. J Comp Neurol 237:1-20.

Bourne HR (1988) Do GTPases direct membrane traffic in secretion? Cell 53:669-671.

Bradley RH, Kitai ST, Wu J-Y (1983) Putative neurotransmitters in neostriatal neurons: a light and electron microscopic study. Soc Neurosci Abstr 9:658.

Capogna M, Gahwiler BH, Thompson SM (1993) Mechanism of $\mu$-opioid receptor-mediated presynaptic inhibition in the rat hippocampus in vitro. J Physiol (Lond) 470:539-558.

Carlin RK, Grab DJ, Cohen RS, Siekovitz P (1980) Isolation and characterization of postsynaptic densities from various brain regions. En- 
richment of different types of postsynaptic dendrites. J Cell Biol $86: 831-843$

Chan J, Aoki C, Pickel VM (1990) Optimization of differential immunogold-silver and peroxidase labeling with maintenance of ultrastructure in brain sections before plastic embedding. J Neurosci Methods 33:113-127.

Chang HT, Kitai ST (1985) Projection neurons of the nucleus accumbens: an intracellular labeling study. Brain Res 347:112-116.

Chieng B, Christie MJ (1994) Inhibition by opioids acting on $\mu$-receptors of GABAergic and glutamatergic postsynaptic potentials in single rat periaqueductal gray neurones in vitro. Br J Pharmacol 113:303-309.

Churchill L, Bourdelais A, Austin M, Zahm DS, Kalivas PW (1991) $\gamma$-Aminobutyric acid and $\mu$-opioid receptor localization and adaptation in the basal forebrain. In: The basal forebrain (Napier TC, ed), pp 101-117. New York: Plenum.

Costall B, Fortune DH, Naylor RJ (1978) The induction of catalepsy and hyperactivity by morphine administered directly into nucleus accumbens of rats. Eur J Pharmacol 49:49-64.

Cunningham ST, Kelly AE (1992) Opiate infusion into nucleus accumbens: contrasting effects on motor activity and responding for conditioned reward. Brain Res 588:104-114.

Dingledine R (1981) Possible mechanisms of enkephalin action on hippocampal CA1 pyramidal neurons. J Neurosci 1:1022-1035.

Drake CT, Bausch SB, Milner TA, Chavkin C (1997) GIRK1 immunoreactivity is present predominantly in somata dendrites and dendritic spines in the CA1 region of the hippocampus. Proc Natl Acad Sci USA, in press.

Edwards FA (1995) Anatomy and electrophysiology of fast central synapses lead to a structural model for long-term potentiation. Physiol Rev 75:759-787.

Galarraga E, Bargas J, Sierra A, Acevas J (1989) The role of calcium in the repetitive firing of neostriatal neurons. Exp Brain Res 75:157-168.

Gerfen CR (1988) Synaptic organization of the striatum. J Electron Microsc Technol 10:265-281.

Goeders NE, Lane JD, Smith JE (1984) Self-administration of methionine enkephalin in the nucleus accumbens. Pharmacol Biochem Behav 20:451-455

Gracy KN, Pickel VM (1996) Ultrastructural immunocytochemical localization of the $N$-methyl-D-aspartate receptor and tyrosine hydroxylase in the shell of the rat nucleus accumbens. Brain Res 739:169-181.

Hakan RL, Henriksen SJ (1987) Systemic opiate administration has heterogenous effects on activity recorded from nucleus accumbens neurons in vivo. Neurosci Lett 83:307-312.

Heijna MH, Padt M, Hogenboom F, Porthoghese PS, Mulder AH, Schoffelmeer ANM (1990) Opioid receptor-mediated inhibition of dopamine and acetylcholine release from rat brain slices: differences between nucleus accumbens, olfactory bulb, and frontal cortex in receptor types involved. Eur J Pharmacol 181:267-278.

Hendry SHC, Houser CR, Jones EG, Vaughn JE (1983) Synaptic organization of immunocytochemically identified GABA neurons in the monkey sensory-motor cortex. J Neurocytol 12:639-660.

Hubner CB, Koob GF (1990) The ventral pallidum plays a role in mediating cocaine and heroin self-administration in the rat. Brain Res 508:20-29.

Hsu S-M, Raine L, Fanger H (1981) Use of avidin-biotin-peroxidase complex (ABC) immunoperoxidase techniques: a comparison between ABC and unlabeled antibody (PAP) procedures. J Histochem Cytochem 29:577-580.

Jiang ZG, North RA (1992) Pre- and postsynaptic inhibition by opioids in rat striatum. J Neurosci 12:356-361.

Johnson SW, North RA (1992) Opioids excite dopamine neurons by hyperpolarization of local interneurons. J Neurosci 12:483-488.

Kalivas PW, Churchill L, Klitenick MA (1993) GABA and enkephalin projection from the nucleus accumbens and ventral pallidum to the ventral tegmental area. Neuroscience 57:1047-1060.

Kaneko T, Minami M, Satoh M, Mizuno N (1995) Immunocytochemical localization of $\mu$-opioid receptor in the rat caudate-putamen. Neurosci Lett 184:149-152.

Kita H, Kitai ST (1988) Glutamate decarboxylase immunoreactive neurons in rat neostriatum: their morphological types and populations. Brain Res 447:346-352.

Lambert NA, Harrison NL, Taylor TJ (1991) Evidence for mu opiate receptors in inhibitory terminals in area CA1 of rat hippocampus. Neurosci Lett 124:101-104.

Leranth C, Pickel VM (1989) Electron microscopic pre-embedding dou- ble immunostaining methods. In: Tract tracing methods 2, recent progress (Heimer L, Zaborszky L, eds), pp 129-172. New York: Plenum.

Lupica CR (1995) $\delta$ and $\mu$ enkephalins inhibit spontaneous GABAmediated IPSCs via a cyclic AMP-independent mechanism in the rat hippocampus. J Neurosci 15:737-749.

Madison DV, Nicoll RA (1988) Enkephalin hyperpolarizes interneurons in the rat hippocampus. J Physiol (Lond) 398:123-130.

Manabe T, Renner P, Nicoll RA (1992) Postsynaptic contribution to long-term potentiation revealed by the analysis of miniature synaptic currents. Nature 355:50-55.

Mansour A, Khachaturian H, Lewis ME, Akil H, Watson SJ (1987) Autoradiographic differentiation of mu, delta, and kappa opioid receptors in the rat forebrain and midbrain. J Neurosci 7:2445-2464.

Mansour A, Fox CF, Burke S, Akil H, Watson SJ (1995) Immunohistochemical localization of the cloned $\mu$-opioid receptor in the rat CNS. J Chem Neuroanat 8:283-305.

Meyer ME, Meyer ME (1993) Behavioral effects of the $\mu$-opioid peptide agonists DAMGO, DALDA, and PL017 on locomotor activities. Pharmacol Biochem Behav 46:391-395.

Meyer ME, McLaurin BI, Allen M, Meyer ME (1994) Biphasic effects of intra-accumbens $\mu$-opioid peptide agonist DAMGO on locomotor activities. Pharmacol Biochem Behav 47:827-831.

Mizoguchi A, Kim S, Ueda T, Kikuchi A, Yorifuji H, Hirowawa N, Takai Y (1990) Localization and subcellular distribution of smg p25A, a ras p21-like GTP-binding protein, in rat brain. $J$ Biol Chem 265: 11872-11879.

Moriwaki A, Wang J-B, Svingos AL, Van Bockstaele E, Cheng PY, Pickel VM, Uhl GR (1996) $\mu$-Opiate receptor immunoreactivity in the rat central nervous system. Neurochem Res 21:1315-1330.

North RA, Williams JT, Suprenant A, Christie MJ (1987) $\mu$ and $\delta$ opioid receptors both belong to a family of receptors that are couples to potassium channels. Proc Natl Acad Sci USA 84:5487-5491.

Oertel WH, Mugnaini E (1983) Two classes of GABAergic neurons represent the majority of neostriatal neurons in the rat. Soc Neurosci Abstr 9:14.

Pasik P, Pasik T, Holstein GR, Hamori J (1988) GABAergic elements in the neuronal circuits of the monkey neostriatum: a light and electron microscopic immunocytochemical study. J Comp Neurol 270:157-170.

Paxinos G, Watson C (1986) The rat brain in stereotaxic coordinates. New York: Academic.

Pert A, Sivit C (1977) Neuroanatomical focus for morphine and enkephalin-induced hypermotility. Nature 265:645-647.

Peters A, Palay SL, Webster H deF (1991) The fine structure of the nervous system, neurons, and their supporting cells, 3rd Ed. New York: Oxford UP.

Pickel VM, Towle AC, Joh TH, Chan J (1988) Gamma-aminobutyric acid in the medial rat nucleus accumbens: ultrastructural localization in neurons receiving monosynaptic input from catecholaminergic afferents. J Comp Neurol 272:1-14.

Ponce A, Bueno E, Kentros C, Vega-Saenz de Miera E, Chow A, Hillman D, Chen S, Zhu L, Wu MB, Wu X, Rudy B, Thornhill WB (1996) G-protein-gated inward rectifier $\mathrm{K}^{+}$channel proteins (GRK1) are present in the soma and dendrites as well as in nerve terminals of specific neurons in the brain. J Neurosci 16:1990-2001.

Preston RJ, Bishop GA, Kitai ST (1979) Medium spiny neuron projection from the rat striatum: an intracellular horseradish peroxidase study. Brain Res 183:253-263.

Reynolds ES (1963) The use of lead citrate at high $\mathrm{pH}$ as an electronopaque stain in electron microscopy. J Cell Biol 17:208.

Ribak CE, Vaughn JE, Roberts E (1979) The GABA neurons and their axon terminals in rat corpus striatum as demonstrated by GAD immunocytochemistry. J Comp Neurol 187:261-284.

Seward E, Hammond C, Henderson G (1991) Mu-opioid receptormediated inhibition of the N-type calcium channel. Proc R Soc Lond [Biol] 244:129-135.

Siggins GR, Martin G, Yuan X, Nie Z, Madamba S (1995) Opiate modulation of glutamatergic transmission in nucleus accumbens neurons in vitro. Analgesia 1:728-733.

Smith AD, Bolam JP (1990) The neural network of the basal ganglia as revealed by the study of synaptic connections of identified neurons. Trends Neurosci 13:259-265.

Surratt CK, Johnson PS, Moriwaki A, Seidleck BK, Blaschak CJ, Wang JB, Uhl GR (1994) $\mu$-Opiate receptor, charged transmembrane do- 
main amino acids are critical for agonist recognition and intrinsic activity. J Biol Chem 269:20548-20553.

Svingos AL, Moriwaki A, Wang JB, Uhl GR, Pickel VM (1995) Extrasynaptic sites for enkephalin modulation through $\mu$-opioid receptors in rat nucleus accumbens. Analgesia 1:774-777.

Svingos AL, Moriwaki A, Wang JB, Uhl GR, Pickel VM (1996) Ultrastructural immunocytochemical localization of $\mu$-opioid receptors in rat nucleus accumbens: extrasynaptic plasmalemmal distribution and association with Leu ${ }^{5}$-enkephalin. J Neurosci 16:4162-4173.

Tempel A, Zukin S (1987) Neuroanatomical patterns of the $\mu, \delta$, and $\kappa$ opioid receptors of rat brain as determined by quantitative in vitro autoradiography. Proc Natl Acad Sci USA 84:4308-4312.

Van Bockstaele EJ, Pickel VM (1995) GABA-containing neurons in the ventral tegmental area project to the nucleus accumbens in rat brain. Brain Res 682:215-221.

West TEG, Wise RA (1988) Effects of naltrexone on nucleus accumbens, lateral hypothalamus, and ventral tegmental self-administration ratefrequency functions. Brain Res 462:126-133.

Westenbroek RE, Sakurai T, Elliot EM, Hell JW, Starr TV, Snutch TP, Catterall WA (1995) Immunocytochemical identification and subcellular distribution of the $\alpha 1 \mathrm{~A}$ subunits of brain calcium channels. J Neurosci 15:6403-6418.
Wimpey TL, Chavkin C (1991) Opioids activate both an inward and a novel voltage-gated potassium conductance in the hippocampal formation. Neuron 6:281-289.

Xie VW, Morrisett RA, Lewis DV (1992) Mu opioid receptor-mediated modulation of synaptic currents in dentate granule cells of rat hippocampus. J Neurophysiol 68:1113-1120.

Yuan X, Madamba S, Siggins GO (1992) Opioid peptides reduce synaptic transmission in the nucleus accumbens. Neurosci Lett 134:223-228.

Zaborszky L, Heimer L, Eckenstein F, Leranth C (1986) GABAergic input to cholinergic forebrain neurons: an ultrastructural study using retrograde tracing of HRP and double immunolabeling. J Comp Neurol 250:282-295.

Zieglgansberger W, Bayerl J (1976) The activity of opiates in the spinal cord of cat. Brain Res 115:233-242.

Zieglgansberger W, French ED, Siggins GR, Bloom FE (1979) Opioid peptides may excite hippocampal pyramidal neurons by inhibiting adjacent inhibitory interneurons. Science 205:415-417.

Zito KA, Vickers G, Roberts DC (1985) Disruption of cocaine and heroin self-administration following kainic acid lesions of the nucleus accumbens. Pharmacol Biochem Behav 23:1029-1036. 